POLLACK PERIODICA

An International Journal for Engineering and Information Sciences

DOI: $10.1556 / 606.2017 .12 .3 .5$

Vol. 12, No. 3, pp. 43-54 (2017)

www.akademiai.com

\title{
SYSTEM IDENTIFICATION OF A COMPOSITE BEAM
}

\author{
${ }^{1}$ Milan SOKOL, ${ }^{2}$ Michal VENGLÁR \\ Department of Structural Mechanics, Faculty of Civil Engineering \\ Slovak University of Technology in Bratislava, Radlinského 11, SK-81005 Bratislava \\ Slovakia, e-mail: ${ }^{1}$ milan.sokol@stuba.sk, ${ }^{2}$ michal.venglar@stuba.sk
}

Received 28 February 2017; accepted 17 May 2017

\begin{abstract}
The primary aim of the paper is to present a simple method for determining the changes in stiffness of a composite beam. The experimental model was made from wood and plaster boards. It was simply supported beam with a length of $4 \mathrm{~m}$. Accelerations were measured at 24 points along the beam. In either case data for intact and damaged models were acquired. The identification of the damage was done using a code developed by the authors. The vertical modeshapes were analyzed, so changes in the stiffness could be detected.
\end{abstract}

Keywords: Modal analysis, System identification, Experimental model, Method for updating finite element model

\section{Introduction}

Nowadays, many scientists [1]-[5] pay attention to different aspects of System Identification (SI) to satisfy increasing demands for safety and the reduction of maintenance costs. In accordance with [6], another reason for paying greater attention to the monitoring of bridges is gradual aging, which is the source of potential damage [7]. E.g. Ahlborn et al. [8] noted that bridge structures in the USA are 43 years old on average. According to Fischer [9], the average age of German bridges is about 45 years and over $65 \%$ of the structures are over the age of 30 years. Slovak bridges are about the same age on average as German bridges [10]. In many cases, the lack of long-term maintenance or periodic inspections can subsequently result in expensive and complete reconstructions. The mentioned fact is confirmed by one of the most recent accidents from the USA. The 94-year-old Greenfield Bridge in Pittsburgh had to be demolished in 
2015 and replaced by a new structure. The Structural Health Monitoring (SHM) of bridges can help prevent these situations.

Dynamic tests of structures are used for some methods of the SHM. In laboratory conditions, it is possible to effectively pay attention to these issues in detail. In order to investigate the connection between two materials in a composite structure, the paper deals with the SHM of an experimental model, i.e. a composite beam. The SHM methodology is applied to an experimental model of a bridge; then, a non-destructive method based on updating the model is employed. Several approaches using the Finite Element Model Updating (FEMU) method were summarized in [11]. The primary aim of the paper is to determine the changes (a decrease) in the stiffness of the test specimen by a code developed by the authors.

The paper consists of several sections. Section 2 introduces the first step of SHM, i.e. preparation of a FE model; Section 3 deals with the experimental measurements; Section 4 is devoted to the Verification and Validation $(V \& V)$ of the Finite Element (FE) model prepared; Section 5 shows the results of the damage assessment of two different scenarios of the damages and finally, the main conclusions are presented in Section 6

\section{Preparation of the finite element model}

The experimental model was made from wood and plaster boards. Three wooden boards (dimensions of $4000 \times 100 \times 20 \mathrm{~mm}$ ) were used for the main beam, and the bridge deck was made of three plasterboard layers (each height was $12.5 \mathrm{~mm}$ ). The deck was $300 \mathrm{~mm}$ wide and $37.5 \mathrm{~mm}$ high. The cross-section of the experimental model is shown in Fig. 1a. The plasterboard layers were connected by pairs of screws every $170 \mathrm{~mm}$ into the main wooden beam. Even though this layout was symmetrical, it was not possible to omit a screw and reduce the connection because the screws were too sparsely distributed. So, the stiffness was changed by adding eight $(4 \times 2)$ extra screws near the left support. This final unsymmetrical layout was the intact structure. The whole length of the experimental model was 4 meters, and a simply supported structural model was assumed. The joint supports were realized using steel bars with a diameter of $12 \mathrm{~mm}$ located in the center of gravity of the cross-section through the holes drilled in the wooden boards (Fig. 1 b and Fig. 1c).

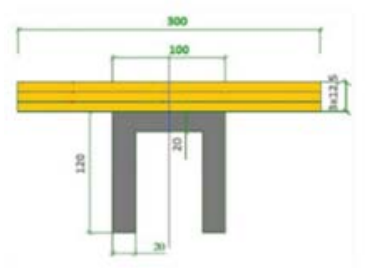

a)

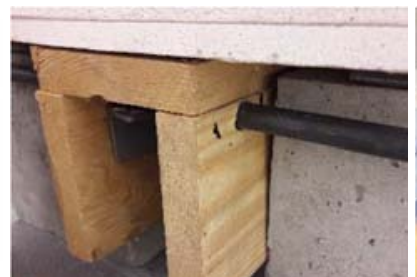

b)

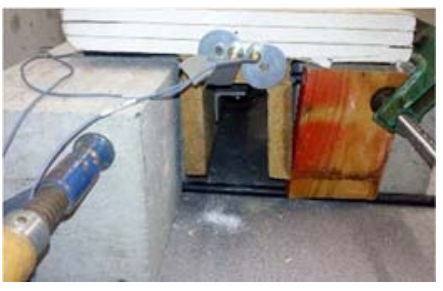

c)

Fig. 1. The cross-section of a) the FE model; b) the experimental model; c) the experimental model at the site of the joint support (dimensions in millimeters) 
In accordance with [12], the preparation of a FE model is the standard procedure for SHM. An accurate FE model is a prerequisite for carrying out the SHM. The 3D numerical model consisted of shell elements with lumped mass elements. The shell elements were used for modeling the 3 wooden and plaster boards. The E-modulus modulus of the wood (7.3 GPa) has been taken from [13], and the E-modulus of the plasterboards (4.1 GPa) was assumed from [14]. The couplings among the plasterboards and wooden beam were assumed to be discrete elements located at the sites corresponding to the experiment.

The modal analysis (Fig. 2 up to Fig. 4) was then performed, and the results were used as the basis for the comparison between the experimental measurements and the validation of the FE model.

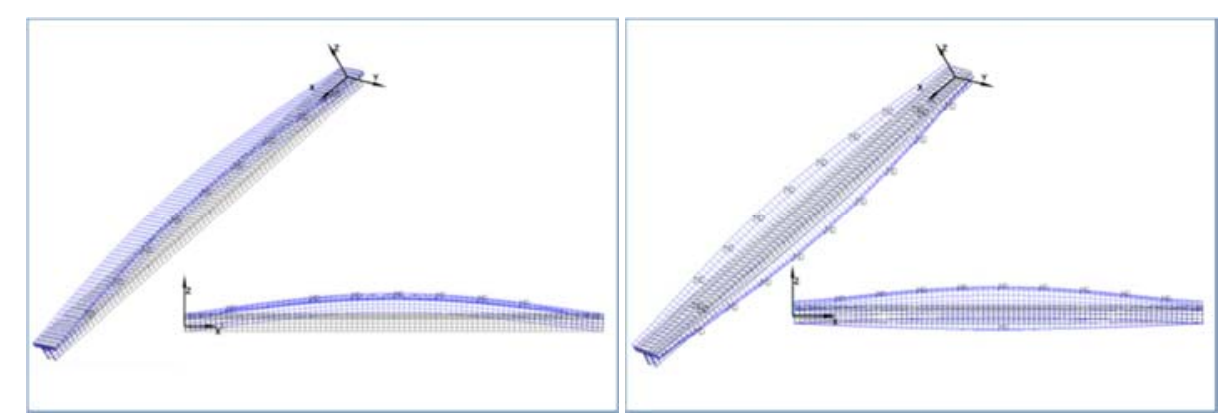

Fig. 2. The $1^{\text {st }}$ mode-shape $\left(f_{1}=10.5 \mathrm{~Hz}\right) \quad$ Fig. 3. The $2^{\text {nd }}$ mode-shape $\left(f_{2}=13.1 \mathrm{~Hz}\right)$

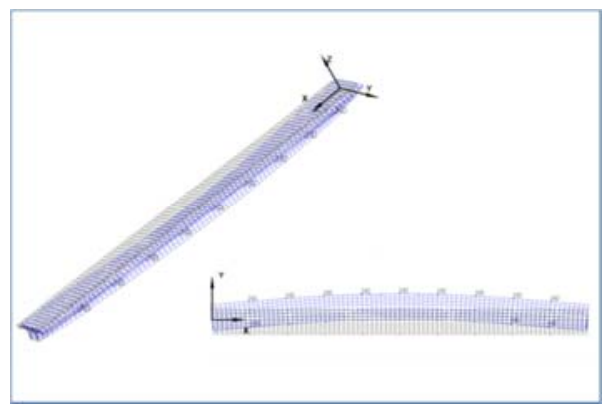

Fig. 4. The $3^{\text {rd }}$ mode-shape $\left(f_{3}=13.9 \mathrm{~Hz}\right)$

\section{Experimental tests}

A National Instruments (NI) CompactRIO 9074 device with 6 Input/Output (I/O) NI 9234 modules was used for the high-accuracy measurements of the accelerations. The six I/O modules represented the possibility of measuring up to 24 channels. The control software was prepared in compliance with the manual [15]. The measurement equipment (a combination of the NI 9234 I/O modules with the PCB Piezotronics 
393B31 accelerometers) permitted measuring frequencies above the value of $0.5 \mathrm{~Hz}$ at intervals of acceleration between the limits $\pm 4.9 \mathrm{~ms}^{-2}$.

The measurements were performed when the temperature reached $20^{\circ} \mathrm{C}$, and the relative humidity was about $62 \%$. Vertical accelerations were measured at 18 points (every $400 \mathrm{~mm}$ ) along the experimental model (Fig. 5a). Six other small accelerometers (MMF KS901.100) were placed in horizontal directions. The spacing of the accelerometers was prepared in accordance with the paper [16] and the book [17]. Vibrations were excited by electromagnetic exciters (Fig. 5b) with a total mass of $18 \mathrm{~kg}$ and a moving mass of $0.6 \mathrm{~kg}$ [18]. The harmonic excitations within the frequencies $5 \mathrm{~Hz}$ to $35 \mathrm{~Hz}$ with $0.5 \mathrm{~Hz}$ step were used. In the case of the asymmetric mode-shapes, the phases of the exciters were shifted 180 degrees; otherwise, the exciters worked synchronously. Finally, several measurements approaching the resonance frequencies were taken.

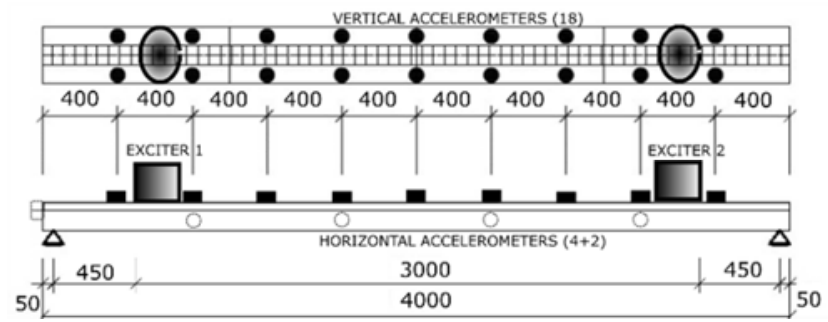

a)

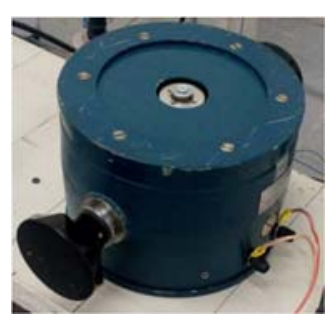

b)

Fig. 5. a) Location of measurement accessories; b) Type of electromagnetic exciter used

The data for the intact and damaged models were acquired. The damage was assumed when the bolts near the left support were loosened in two stages: 4 bolts were unscrewed in the first stage; another 4 bolts were unscrewed in the next stage (Fig. 6).

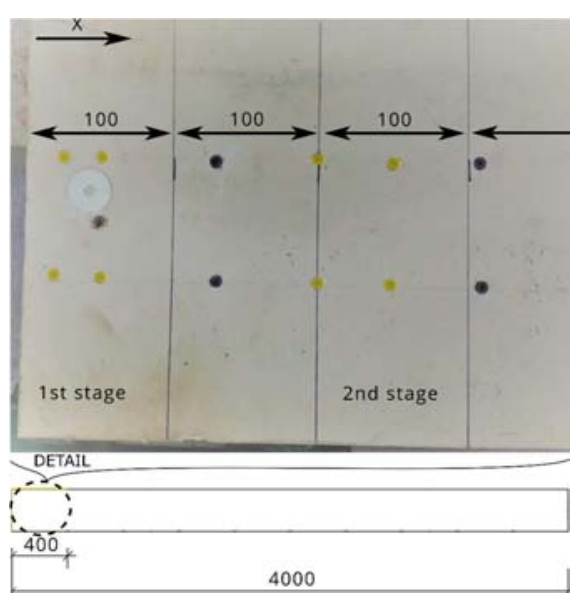

Fig. 6. Damaged site of the beam (dimensions in millimeters) 
Firstly, the measured data were processed using LabVIEW and then ModalVIEW software; the other results were processed using NI DIAdem software. The experimental modal analysis is shown below in Fig. 7 - Fig. 10.

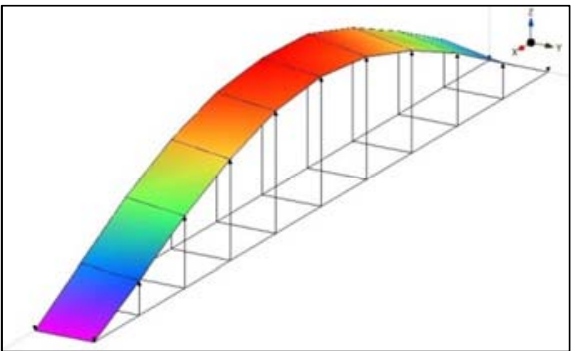

Fig. 7. The $1^{\text {st }}$ measured mode-shape $\left(f_{1}=10.7 \mathrm{~Hz}\right)$

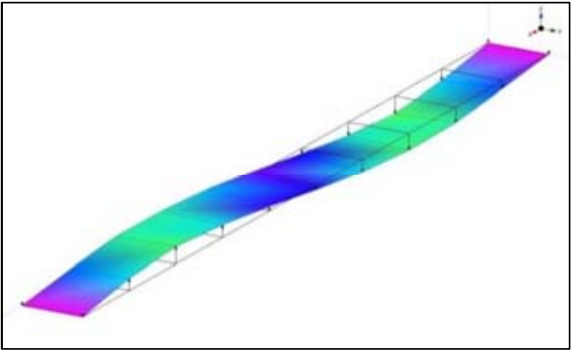

Fig. 9. The $4^{\text {th }}$ measured mode-shape $\left(f_{4}=24.6 \mathrm{~Hz}\right)$

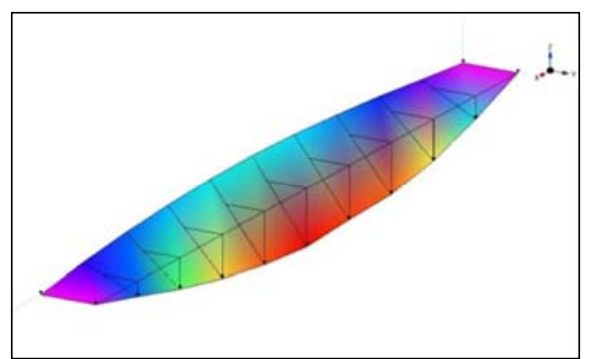

Fig. 8. The $2^{\text {nd }}$ measured mode-shape $\left(f_{1}=12.9 \mathrm{~Hz}\right)$

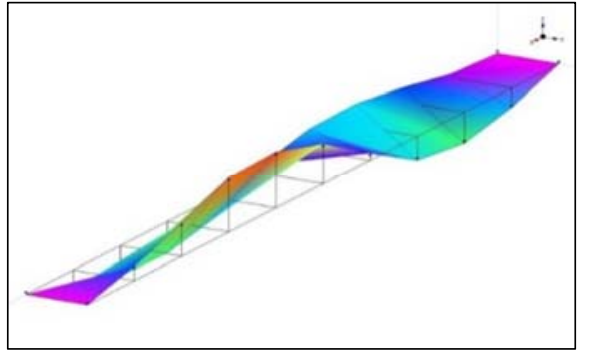

Fig. 10. The $6^{\text {th }}$ measured mode-shape $\left(f_{6}=29.3 \mathrm{~Hz}\right)$

\section{Verification and validation of the model}

Many parameters, e.g. the mass, natural frequencies, mode-shapes and Cross-Modal Accordance Criterion (Cross-MAC) values were checked for the validation procedure of the numerical model in accordance with [19].

Firstly, the mass was checked for the validation of the FE model. The weight of the beam was approximately $49 \mathrm{~kg}$. The accelerometers and exciters (totally $47 \mathrm{~kg}$ ) were assumed by the lumped mass elements. The difference in weight of the FE model and the experimental one was ignored (Table I).

Then, the first six global mode-shapes were compared; the corresponding frequencies are in Table II. 
Table I

Comparison of the mass used

\begin{tabular}{|r|l|l|l|}
\hline & $\begin{array}{c}\text { Experimental } \\
\text { model (A) }\end{array}$ & Numerical model (B) & $\begin{array}{c}\text { Error [\%], } \\
\frac{(A-B)}{\max (A, B)}\end{array}$ \\
\hline Beam & $49.1 \mathrm{~kg}$ & $49.4 \mathrm{~kg}$ & -0.61 \\
Accessories & $47.1 \mathrm{~kg}$ & $47.1 \mathrm{~kg}$ & \pm 0.00 \\
Total & $96.2 \mathrm{~kg}$ & $96.5 \mathrm{~kg}$ & -0.31 \\
\hline
\end{tabular}

Table II

Comparison of the dynamic characteristics

\begin{tabular}{|c|l|l|l|}
\hline $\begin{array}{c}\text { No. of the mode-shape } \\
\text { (direction) }\end{array}$ & $\begin{array}{c}\text { Measured } \\
\text { frequency (A) }\end{array}$ & $\begin{array}{c}\text { Calculated frequency } \\
(\mathrm{B})\end{array}$ & $\begin{array}{c}\text { Error [\%] } \\
(A-B)\end{array}$ \\
\hline $1^{\text {st }}-$ in $z$ direction & $10.7 \mathrm{~Hz}$ & $10.5 \mathrm{~Hz}$ & +1.89 \\
$2^{\text {nd }}-$ around $x$ axis & $12.9 \mathrm{~Hz}$ & $13.1 \mathrm{~Hz}$ & -1.53 \\
$3^{\text {rd }}-$ in $y$ direction & $13.8 \mathrm{~Hz}$ & $13.9 \mathrm{~Hz}$ & -0.72 \\
$4^{\text {th }}-$ in $z$ direction & $24.6 \mathrm{~Hz}$ & $23.1 \mathrm{~Hz}$ & +6.10 \\
$5^{\text {th }}-$ in $y$ direction & $28.4 \mathrm{~Hz}$ & $27.1 \mathrm{~Hz}$ & +4.58 \\
$6^{\text {th }}-$ around $x$ axis & $29.3 \mathrm{~Hz}$ & $28.4 \mathrm{~Hz}$ & +3.07 \\
\hline
\end{tabular}

The method using the Modal Assurance Criterion (MAC) is based on a direct comparison of the mode-shapes [20]. The MAC value could be either 0 (disagreement among the mode-shapes) or 1 (for full conformity), based on the following formula:

$$
\operatorname{MAC}(i, j)=\frac{\left(\Phi_{i}^{A^{T}} \Phi_{j}^{B}\right)^{2}}{\left(\Phi_{i}^{A^{T}} \Phi_{j}^{A}\right)\left(\Phi_{i}^{B^{T}} \Phi_{j}^{B}\right)}
$$

where $\Phi_{i}^{A}$ is the $i$-th mode-shape vector of the undamaged structure, and $\Phi_{j}^{B}$ is the $j$-th mode-shape vector of the damaged structure. The Cross-MAC values were calculated for a comparison of the measured (marked by the letter $A$ ) and the calculated $(B)$ modeshapes. In accordance with the position of the accelerometers, the mode-shapes in the $z$ direction and around the $x$ direction were considered for this comparison as seen in Table III.

The results in this section confirm that the FE model was verified and validated with a sufficient degree of accuracy. The damage assessment followed the successful completion of the $\mathrm{V} \& \mathrm{~V}$. 


\section{Table III}

Cross-MAC values (A - measured mode-shapes, B - calculated mode-shapes)

\begin{tabular}{|c|l|l|l|l|}
\hline B & $\begin{array}{c}1^{\text {st }}-\text { in } \mathrm{Z} \\
\text { direction }\end{array}$ & $\begin{array}{c}2^{\text {nd }}-\text { around } \\
x \text { axis }\end{array}$ & $\begin{array}{c}4^{\text {th }}-\text { in } z \\
\text { direction }\end{array}$ & $\begin{array}{c}6^{\text {th }}-\text { around } \\
x \text { axis }\end{array}$ \\
\hline $1^{\text {st }}-$ in $z$ direction & 0.98 & 0.02 & 0.00 & 0.00 \\
$2^{\text {nd }}-$ around $x$ axis & 0.09 & 0.91 & 0.00 & 0.00 \\
$4^{\text {th }}-$ in $z$ direction & 0.02 & 0.00 & 0.93 & 0.01 \\
$6^{\text {th }}-$ around $x$ axis & 0.00 & 0.00 & 0.01 & 0.87 \\
\hline
\end{tabular}

\section{Damage detection}

The results obtained for all the stages were evaluated as seen in Table IV, where the comparison of frequencies is shown. The sampling rate and length of the data acquired were chosen for their sufficient resolvable frequency.

\section{Table IV}

Damage detection (the change in natural frequency)

\begin{tabular}{|l|c|c|c|}
\hline Mode-shape Stage & Intact structure & $\begin{array}{c}1^{\text {st }} \text { stage }(4 \\
\text { bolts } \\
\text { loosened })\end{array}$ & $\begin{array}{c}2^{\text {nd }} \text { stage }(8 \\
\text { bolts } \\
\text { loosened })\end{array}$ \\
\hline $1^{\text {st }}-$ in $z$ direction & $10.74 \mathrm{~Hz}$ & $10.66 \mathrm{~Hz}$ & $10.59 \mathrm{~Hz}$ \\
\hline
\end{tabular}

Another method was then applied. The MAC values (Table V) were calculated for the damage comparison. They proved that the changes in frequencies are influenced by the damage. The greater the damage, the greater the change in the frequencies. However, the changes in frequencies still reached only fractions of the percentages. So, the use of only the frequencies for the damage evaluation is not sufficient. More attention should be paid to the mode-shapes.

\section{Table V}

MAC values (the $1^{\text {st }}$ mode-shape)

\begin{tabular}{|c|l|l|l|}
\hline The $1^{\text {st }}$ mode-shape & Intact structure & $\begin{array}{c}1^{\text {st }} \text { stage }(4 \\
\text { bolts loosened })\end{array}$ & $\begin{array}{c}2^{\text {nd }} \text { stage }(8 \\
\text { bolts loosened })\end{array}$ \\
\hline Intact structure & 1.000 & 0.996 & 0.991 \\
$1^{\text {st }}$ stage (4 bolts loosened) & 0.996 & 1.000 & 0.995 \\
$2^{\text {nd }}$ stage ( 8 bolts loosened $)$ & 0.991 & 0.995 & 1.000 \\
\hline
\end{tabular}

After comparing the natural frequencies and the MAC values for the damage detection, a code developed in our institution was prepared and applied for the damage assessment. The code was outlined in [21] in more detail. All the data acquired were firstly smoothed by approximation functions using the software Mathematica before the data were directly used in the code as the input data. In the numerical calculations, 
many more elements and nodes were needed than those where the sensors had been applied. So, smoothing of the data was necessary to get more accurate results. Fig. 11 shows an example of the measured values of mode-shape $Y_{(i)}$ and the smoothed function for the $1^{\text {st }}$ mode-shape.

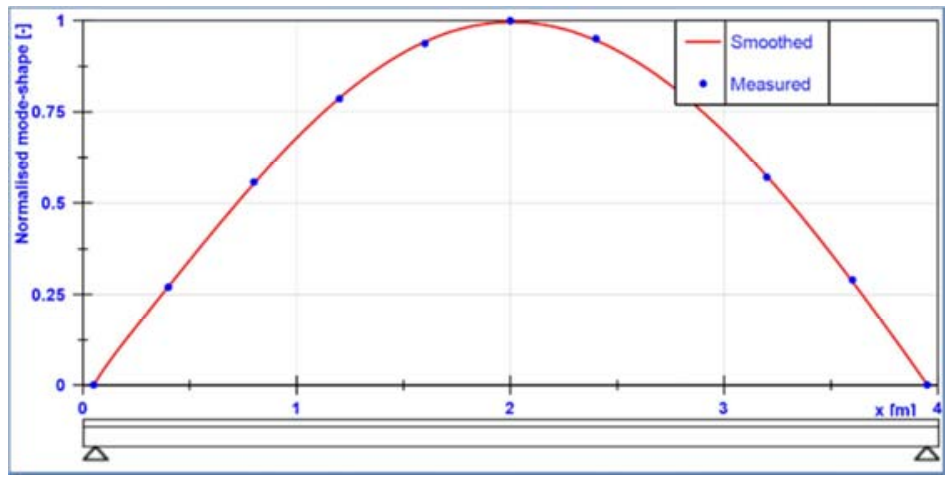

Fig. 11. The $1^{\text {st }}$ smoothed mode-shape

Fig. 12 shows the program flowchart, where each element (i) has its characteristic values of bending stiffness $E I_{(i)}$; mode-shape measured displacement $Y_{(i)}$; calculated displacement of mode-shape $Y_{-} Y_{(i)}$ and the corresponding slopes $R O T_{(i)}$ for the measured and the calculated displacements respectively. The slopes were calculated numerically. $X_{(i)}$ is calculated in every cycle,

$$
X_{(i)}=Y_{(i)}-Y_{-} Y_{(i)},
$$

where $X_{(i)}$ is the value of the difference between the measured and the calculated displacements; then the increment $I N C_{(i)}$ or decrement $D E C_{(i)}$ of the stiffness $E I_{(i)}$ can be determined. The end of the iteration cycle is obtained when the FAULT value is equal to or smaller than the LIMIT value (Fig. 12). A compromise between the calculation time and acceptable degree of accuracy (LIMIT value) was reached using 36 elements along the bridge model.

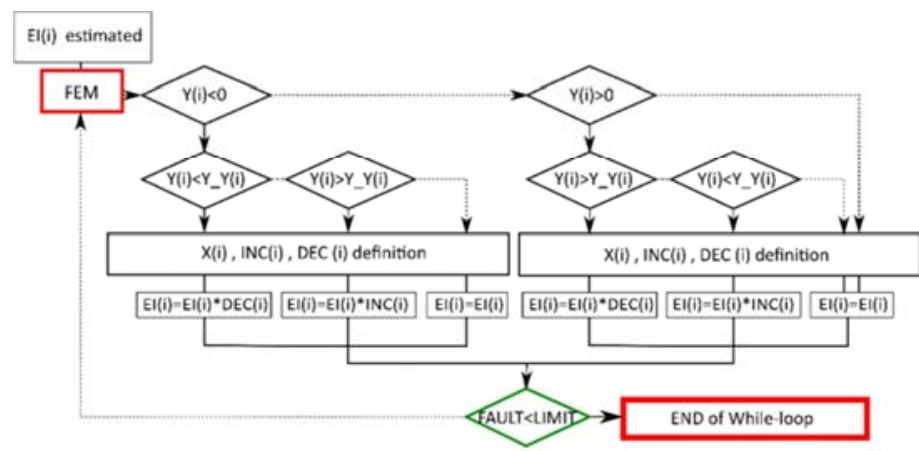

Fig. 12. The program flowchart (true - solid line, false - dashed line) 
The mode-shape without a change in the stiffness of the structure was recalculated at the beginning with the above-mentioned program. It is marked as an intact structure. The estimated moment of inertia of the entire cross section was applied to the developed program as the input value and is marked with a dotted line (see Fig. 13). The solid line represents the identified moment of inertia of the intact structure. The result is nonsymmetrical because of the reasons explained in Section 2.

The calculations subsequently continued with the data for the damaged beam. As mentioned before, the first damaged stage represents a loosening of 4 bolts, which is represented by the dot-dashed line in Fig. 13. During the second stage, another 4 bolts were loosened, i.e. the dashed line in Fig 13.

The changes in the detail shown in Fig. 13 are worth commenting on. Even though the change in stiffness is not that significant, the damage was successfully identified in both stages; however, the site identified is a little bit larger than that of the actual structures. A small inaccuracy was identified at a site $3.4 \mathrm{~m}$ from the left support for the first stage of damage. It could have been caused by the sparsely placed accelerometers or by the smoothening function, but the values are still acceptable.

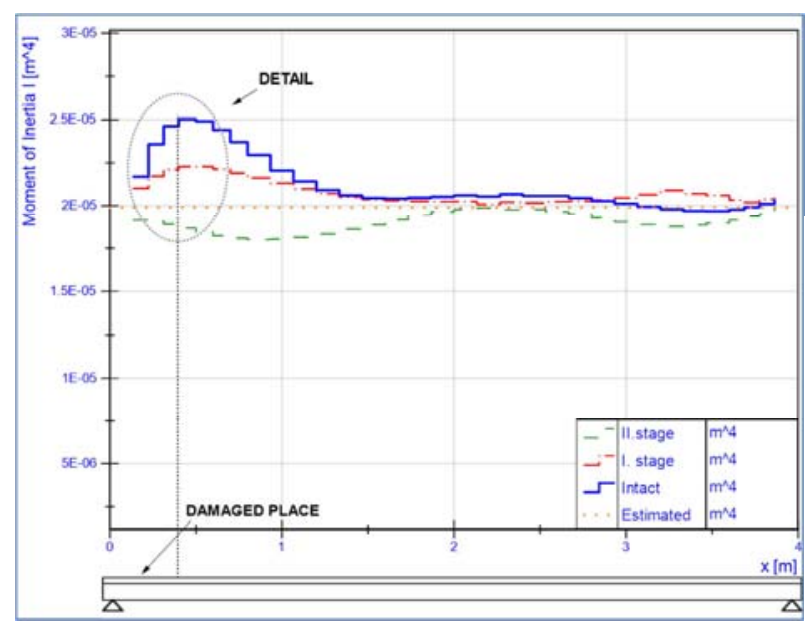

Fig. 13. Damage detection

Two small accelerometers (out of the 24 used) were placed to measure vibrations in the direction of the $x$ axis as is shown in Fig. 14. They are both located at the end of the beam close to the plane between the contact of the two layers, but one of them was connected to the wooden part of the cross section and the second one to the plaster board.

The vibrations measured on the plaster board and the wooden board on the $x$ axis during the damage scenarios proved the results which were previously stated in this section. Fig. 15 shows that the connection between the two materials is undamaged and represents an intact structure. After the application of the $2^{\text {nd }}$ damage scenario, the bending resistance was reduced and the connection loosened, as is shown in Fig. 16. 


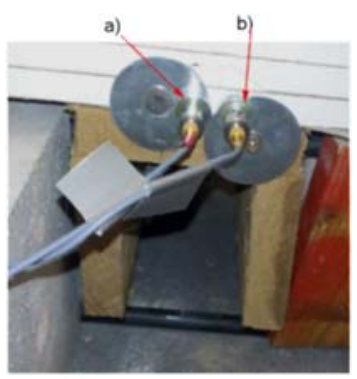

Fig. 14. Accelerometers on the $x$ axis at a) plaster board b) wooden board

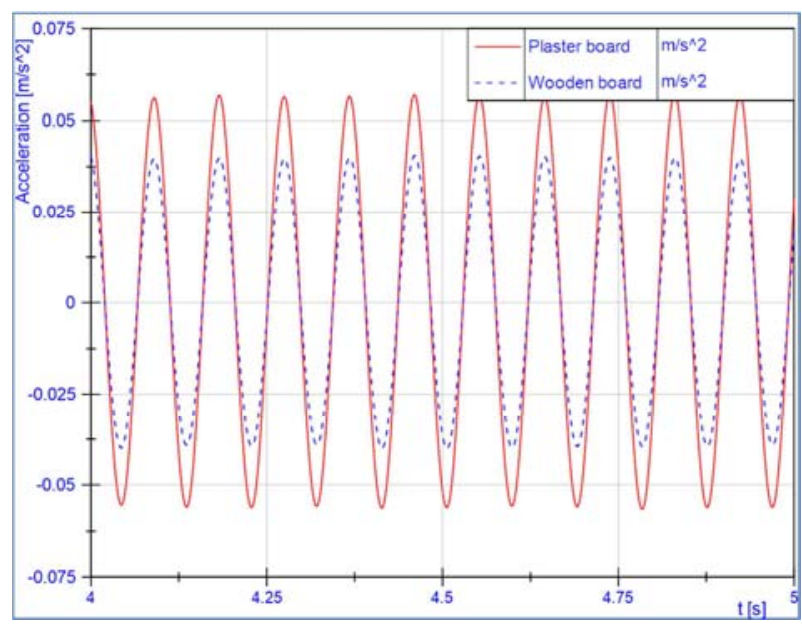

Fig. 15. Comparison of the accelerations in intact structure

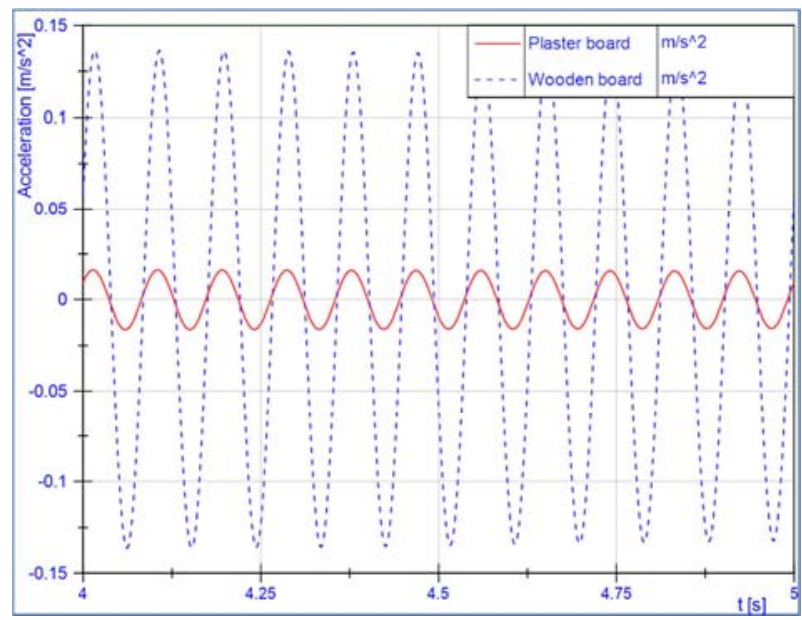

Fig. 16. Comparison of the acceleration in damaged structure 


\section{Conclusion}

The modified FEMU method of SHM was tested experimentally on a composite structure in a laboratory. The FE model was prepared and then successfully verified and validated. The accurate FE model after the successful V\&V can simplify the procedure of damage identification.

Additionally, the assessment of the damage, which was divided into two stages (4 loosened bolts and finally 8 loosened bolts), shows satisfying results. The shear connection damages can be identified by applying the code developed by the authors. Changes in the mode-shapes and the overall response of the structure were also proved by other methods, such as a comparison of the frequencies, the use of the MAC values, and monitoring the degree of the shear connection at the end of the beam. All the methods mentioned indicate that the damage could be detected.

On the other hand, this simple program has shown a degree of uncertainty in the precise localization of the damage. Subsequent research should continue with an improvement of the program to localize the damage more accurately.

\section{Acknowledgements}

This paper was supported by the Slovak Research and Development Agency (SRDA), i.e. a grant from research program No. APVV-0236-12; it was also created with the support of the Ministry of Education, Science, Research and Sport of the Slovak Republic within the Research and Development Operational Programme for the project 'University Science Park of STU Bratislava', ITMS 26240220084.

\section{References}

[1] Collins J., Mullins G., Lewis C., Winters D. State of the practice and art for structural health monitoring of bridge, Research, Development and Technology Turner-Fairbank Highway Research Center, Federal Highway Administration, McLean, 2014.

[2] Wang L., Chan T. H. T. Review of vibration-based damage detection and condition assessment of bridge structures using structural health monitoring, The Second Infrastructure Theme Postgraduate Conference on Rethinking Sustainable Development: Planning, Engineering, Design and Managing Urban Infrastructure, Gardens Point Campus, Queensland University of Technology, Australia, 26 March 2009, pp. 1-15.

[3] Comanducci G., Ubertini F., Materazzi A. L. Structural health monitoring of suspension bridges with features affected by changing wind speed, Journal of Wind Engineering and Industrial Aerodynamics, Vol. 141, 2015, pp. 12-26.

[4] Yarnold M. T., Moon F. L. Temperature-based structural health monitoring baseline for long-span bridges, Engineering Structures, Vol. 86, 2015, pp. 157-167.

[5] Seo J., Hu J., Lee J. Summary review of structural health monitoring applications for highway bridges, Journal of Performance of Constructed Facilities, Vol. 30, No. 4, 2016.

[6] Guan H. Vibration-based structural health monitoring of highway bridges, PhD Thesis, University of California, San Diego, 2006.

[7] Orban Z. Increasing the reliability of the assessment of masonry arch bridges by nondestructive testing, Pollack Periodica, Vol. 1, No. 3, 2006, pp. 45-56. 
[8] Ahlborn T. M., Shuchman R., Sutter L. L., Brooks C. N., Harris D. K., Burns J. W., Endsley K. A. Evans D. C., Vaghefi K., Oats R. C. The state-of-the-practice of modern structural health monitoring for bridges: A comprehensive review, Department of Civil and Environmental Engineering, Michigan Tech Transportation Institute, Michigan Technological University, 2010.

[9] Fischer O. Pre-stressed concrete bridges in Germany, Overview of current new structures, re-analysis and research activities to preserve the existing infrastructure network, Procedia Engineering, Vol. 156, 2016, pp. 103-108.

[10] Paulik P. Bridges in Slovakia, Bratislava, Jaga, 2014.

[11] Carden E. P., Fanning P. Vibration based condition monitoring: A review, Structural Health Monitoring, Vol. 3, No. 4, 2004, pp. 355-377.

[12] Zong Z., Lin X., Niu J. Finite element model validation of bridge based on structural health monitoring, Part I, Response surface-based finite element model updating, Journal of Traffic and Transportation Engineering, Vol. 2, No. 4, 2015, pp. 258-278.

[13] Green D. W., Winandy J. E., Kretschmann D. E. Wood Handbook: Wood as an Engineering Material; Forest Products Laboratory, Forest Service, U.S. Department of Agriculture: Madison, WI, USA, 1999. Chp. 4.

[14] Drywall Systems, Knauf, Iphofen, 2013.

[15] National Instruments, NI LabVIEW for CompactRIO Developer's Guide, Texas, 2013.

[16] Shi Z. Y., Law S. S., Zhang L. M. Optimum sensor placement for structural damage detection, Journal of Engineering Mechanics, Vol. 126, No. 11, 2000, pp. 1173-1179.

[17] Wilson J. S. Sensor technology handbook, Amsterdam, Elsevier, 2004.

[18] Thorby D. Structural dynamics and vibration in practice: an engineering handbook, Amsterdam, Butterworth-Heinemann, 2008.

[19] Thacker B. H., Doebling S. W., Hemez F. M., Anderson M. C., Pepin J. E., Rodriguez E. A. Concepts of model verification and validation, Los Alamos National Laboratory, Los Alamos, 2004.

[20] Venglar M., Sokol M., Aroch R. System identification of a truss beam, Engineering Mechanics 2016: book of full texts, 22nd International Conference on Engineering Mechanics, Svratka, Czech Republic, 9-12 May, 2016, pp. 573-576.

[21] Sokol M., Aroch R., Venglar M., Fabry M., Zivner T. Experience with structural damage identification of an experimental bridge model, Applied Mechanics and Materials: Trends in Statics and Dynamic of Construction, 12th International Conference on New Trends in Statics and Dynamics of Buildings, Bratislava, Slovakia, 16-17 October, Vol. 769, 2015, pp. 192-199. 